\title{
Sorption isotherm study on vacuum and freeze-dried jamun pulp
}

\author{
${ }^{1,2,{ }^{*}}$ Jebitta, R.S., ${ }^{2}$ Allwin, J.S.I. and ${ }^{3}$ Pandian, K.N.S. \\ ${ }^{1}$ Department of Food Processing and Engineering, Karunya Institute of Technology and sciences, \\ Coimbatore, Tamil Nadu, India \\ ${ }^{2}$ Department of Food Technology, Kalasaliagam Academy of research and Education, Srivilliputtur, Tamil \\ Nadu, India \\ ${ }^{3}$ Department of Food Plant Operations, College of Food and Dairy Technology, Alamathi Post, Koduvalli, \\ Chennai, Tamil Nadu, India
}

\author{
Article history: \\ Received: 1 November 2020 \\ Received in revised form: 8 \\ December 2020 \\ Accepted: 29 April 2021 \\ Available Online: 13 \\ February 2022
}

\section{Keywords:}

Drying study,

Sorption isotherm,

Freeze dryer,

Vacuum shelf dryer,

GAB Model,

Jamun Pulp

DOI:

https://doi.org/10.26656/fr.2017.6(1).601

\begin{abstract}
Fruits play the most important role in nutrition. In India many underutilized medicinal fruits are available, and the most important fruit is jamun which is otherwise called black plum. Drying of underutilized jamun fruits helps in minimizing their post-harvest loss which occurs during harvesting season. The freeze-dried powder results with polar sites in molecular structure material which is occupied with water in wet conditions. During drying the molecules which were holding the water particles are attracted closely to each other. The study on sorption isotherms was carried out on the dried powder. These results gave a suitable model to fit sorption behaviour. The empirical equations frequently used to model drying kinetics are Newton, Henderson-Pabis, Page, Modified Page, WangSingh, Logarithmic, Two-Terms, Modified Henderson-Pabis and many mathematical models to describe the water sorption behaviour of foods. The GAB equation was fitted as the best fit for vacuum-dried jamun pulp powder stored at $27^{\circ} \mathrm{C}$ and $37^{\circ} \mathrm{C}$.
\end{abstract}

\section{Introduction}

The important thermodynamic tool used for the interaction between a food component and water is the sorption isotherm. This sorption isotherm gives information for food processing operation based on the equilibrium moisture content of that product with relation to the relative humidity of that particular surrounding maintained at a constant temperature. The sorption isotherm models can predict the amount of water that can be held by the food material if it is exposed to air at a particular relative humidity.

This moisture absorption of the equilibrium moisture content obtained during the study mainly depends on the environmental relative humidity with the composition of the food. In general, the consumption of berries has increased during the last decade and berries of different kinds are widely consumed in many countries (Heinonen, 2007; Szajdek and Borowska, 2008). Dried jamun fruit has been used as food ingredients on fruit infusion. Over recent decades the post-harvest technology used for preserving berry fruit is drying. Drying will prolong the shelf life of the fruit with its quality. By lowering the moisture content through drying there will be a decrease in spoilage and contamination during storage reported by the authors (Akpinar and Bicer, 2005). Drying of jamun fruit is considered as an important source of phenols, antioxidants, flavonoids minerals and is used as an ingredient in functional foods.

Simulation of the drying process through mathematical modelling is an important tool used to minimize operative problems such as product damage and excessive consumption of energy, among others (Stamatios and Vassilios, 2004) The empirical equations frequently used to model drying kinetics are Newton, Henderson-Pabis, Page, Modified Page, Wang-Singh, Logarithmic, Two-Terms, Modified Henderson-Pabis and many mathematical models to describe the water sorption behaviour of foods can be found in the literature (Ahrne, 2004). The Guggenheim-Anderson-de Boer (GAB) model is considered to be the most versatile and the best one for fitting the sorption data for the majority of food products in a water activity range of $0-0.85$ (Lomauro et al., 1985; Prothon and Ahrne, 2004). A common way of presenting the relationship between aw and water content is a sorption isotherm (Gondek and 
Lewicki, 2005) however, there is no direct relationship between these two parameters. The shape of the curves depends, above all, on the composition and structure of the material, temperature, and pressure. Knowledge of the moisture sorption characteristics is crucial for shelflife predictions and determination of critical moisture and water activity for acceptability of products that deteriorate mainly by moisture gain and are important in drying, packaging and storage (Bianco et al., 2001).

\section{Materials and methods}

\subsection{Sample preparation}

Mature Jamun fruits were directly obtained from producers in the region of Pollachi. The fruits were sorted by their maturity and the fully ripped fruits were washed in normal tap water. The free water in the fruit was removed using a hairdryer and wiped down using tissue papers. Pre-weighed $100 \mathrm{~g}$ of jamun fruit was packed in each polypropylene zip lock bag and kept in a deep freezer at $-30^{\circ} \mathrm{C}$ for further use.

\subsection{Drying conditions}

The stored jamun fruits were taken from the deep freezer and kept at room temperature to reach their normal state. Jamun pulp was extracted manually by separating the pulp from the seed. Approximately $500 \mathrm{~g}$ of pulp was taken for the drying experiment.

\subsection{Vacuum shelf drying}

The pulp of jamun fruits was kept in stainless steel trays and arranged in a vacuum shelf drier. The process parameters in vacuum drying of jamun pulp were vacuum pressure, the temperature of drying and loading weight.

\subsection{Freeze drying}

The selection of the freezing conditions is very important to optimize the efficiency of the freezing process and to preserve the biological microstructure of the samples. Freeze drying was carried out using a laboratory freeze dryer (Freeze Mobile 24, Virtis Company, Inc., Gardiner, NY). The thawed jamun pulp was poured into a stainless pan to form a layer of $10 \mathrm{~mm}$. The samples were placed at $25^{\circ} \mathrm{C}$ for $24 \mathrm{hrs}$ before transferring to the freeze dryer. The vacuum pressure of the dryer was set at $20 \mathrm{~Pa}$, the plate temperature was $-20^{\circ}$ $\mathrm{C},-30^{\circ} \mathrm{C}$ and $-40^{\circ} \mathrm{C}$, and the condenser was at $60^{\circ} \mathrm{C}$. The residence time needed to dry the jamun pulp to below $0.05 \mathrm{~kg}$ water $/ \mathrm{kg}$ dry solids was determined when the vacuum pressure had dropped to $30 \mathrm{mTorr}(4 \mathrm{~Pa})$.

\subsection{Adsorption isotherm determination}

An adsorption isotherm study was done based on Gondek and Lewicki (2005) methods. A known weight of $5 \mathrm{~g}$ of samples was taken and placed in desiccators which contains nine different saturated salt solutions in each desiccator. The saturated salt solutions are $\mathrm{LiCl}$ ( $a w$ $=0.113)$, potassium acetate $(a w=0.225), \mathrm{MgCl}_{2}(a w=$ $0.329), \mathrm{K}_{2} \mathrm{CO}_{3}(a w=0.438), \operatorname{Mg}\left(\mathrm{NO}_{3}\right)_{2}(a w=0.529)$, $\mathrm{NaNO}_{2}(a w=0.648), \mathrm{NaCl}(a w=0.753),\left(\mathrm{NH}_{4}\right)_{2} \mathrm{SO}_{4}(a w$ $=0.810)$, Thymol was placed in the desiccators containing $\mathrm{NaCl},\left(\mathrm{NH}_{4}\right)_{2} \mathrm{SO}_{4}$ in order to prevent the growth of mould. The samples were weighed periodically till they attained equilibrium, after which they were analysed for moisture content. To establish moisture sorption isotherms, the equilibrium moisture contents determined by the static gravimetric method, were plotted against water activity. For the study the samples were kept in both $37^{\circ} \mathrm{C}$ and $27^{\circ} \mathrm{C}$.

\subsection{Sorption isotherm model fitting}

The data obtained corresponding to $a_{w}$ and moisture content at the temperatures studied was adjusted to Henderson, Hasley, Iglesias and Chirife and GAB.

$$
\begin{array}{cc}
\text { Henderson } & M=a\left(-\ln \left(1-a_{w}\right)\right)^{n} \\
\text { Hasley model } & M=a\left(-\ln \left(a_{w}\right)\right)^{n} \\
\text { Iglesias and Chirife } & \ln \left(M+\left(M^{2}+M_{0.5}\right)^{\frac{1}{2}}\right)=b a_{w}+c \\
\text { GAB } & M=\frac{M_{0} C K a_{w}}{\left(1-K a_{w}\right)\left(1-K a_{w}+C K a_{w}\right)} \\
& \mathrm{C}=\mathrm{C}_{\mathrm{o}} \exp \left(\Delta \mathrm{H}_{\mathrm{c}} / \mathrm{RT}\right) \\
\mathrm{K} & =\mathrm{K}_{\mathrm{o}} \exp \left(\Delta \mathrm{H}_{\mathrm{k}} / \mathrm{RT}\right)
\end{array}
$$

where $\mathrm{M}$ is the equilibrium moisture content, $\mathrm{a}_{\mathrm{w}}$ water activity, $\mathrm{C}, \mathrm{K}$ are GAB model constant, $\mathrm{a}, \mathrm{b}$, c fitting model constant, $\mathrm{M}_{\mathrm{o}}$ monolayer moisture content, $\mathrm{C}$ is related to first layer heat of sorption factor, $\mathrm{K}$ is factor correcting $\mathrm{c}$ and are related to monolayer and multilayer properties (Bajpai and Tiwari, 2013)

\subsection{Model validation}

In our study the Henderson, Hasley, Iglesias and Chirife and $\mathrm{GAB}$ equations are used to model the moisture isotherm for jamun pulp powder dried under both vacuum and freeze dryer. The models were validated with the experimental data using nonlinear regression. The calculations were analysed using the MATLAB Version 5.3 (Mathworks, Inc., Natick, MA). The statistical validity to fit the models were evaluated using statistical parameters such as the root mean square error (RMSE) and determination of co-efficient $\left(R^{2}\right)$. Models are used to show the relationship between the equilibrium moisture content, water activity and temperature. Best fit for both the samples were evaluated 
based on the model run with high $\mathrm{R}^{2}$, lowest Chi-square and RMSE value which is close to zero.

$$
\begin{aligned}
& R M S E=\sqrt{\frac{\sum_{i=1}^{N}\left(M_{\exp }-M_{\text {pre }}\right)}{M_{\exp }}} \times 100 \\
& \lambda^{2}=\frac{\sum_{i=\mathbf{1}}^{N}\left(\boldsymbol{M}_{\boldsymbol{e x p}}-\boldsymbol{M}_{\text {pre }}\right)^{2}}{(\boldsymbol{N}-\mathbf{z})}
\end{aligned}
$$

\section{Results and discussion}

\subsection{Sorption isotherm}

The sorption isotherm for jamun pulp obtained by vacuum-dried and freeze-dried powder were shown in Figure 1 and Figure 2. The equilibrium moisture content tends to decrease with respect to an increase in temperature on given particular water activity. Similar results were obtained by Catelam et al. (2011). It was observed that the increase in temperature has a very evident effect on the equilibrium moisture sorption isotherm on both the vacuum and freeze-dried samples. Garrone et al. (2010) found that the isotherms of pineapple, mango and guava dried under vacuum, at temperatures of 25 and $50^{\circ} \mathrm{C}$, showed the same behaviour observed by Silva et al. (2010). In Figure 1, a
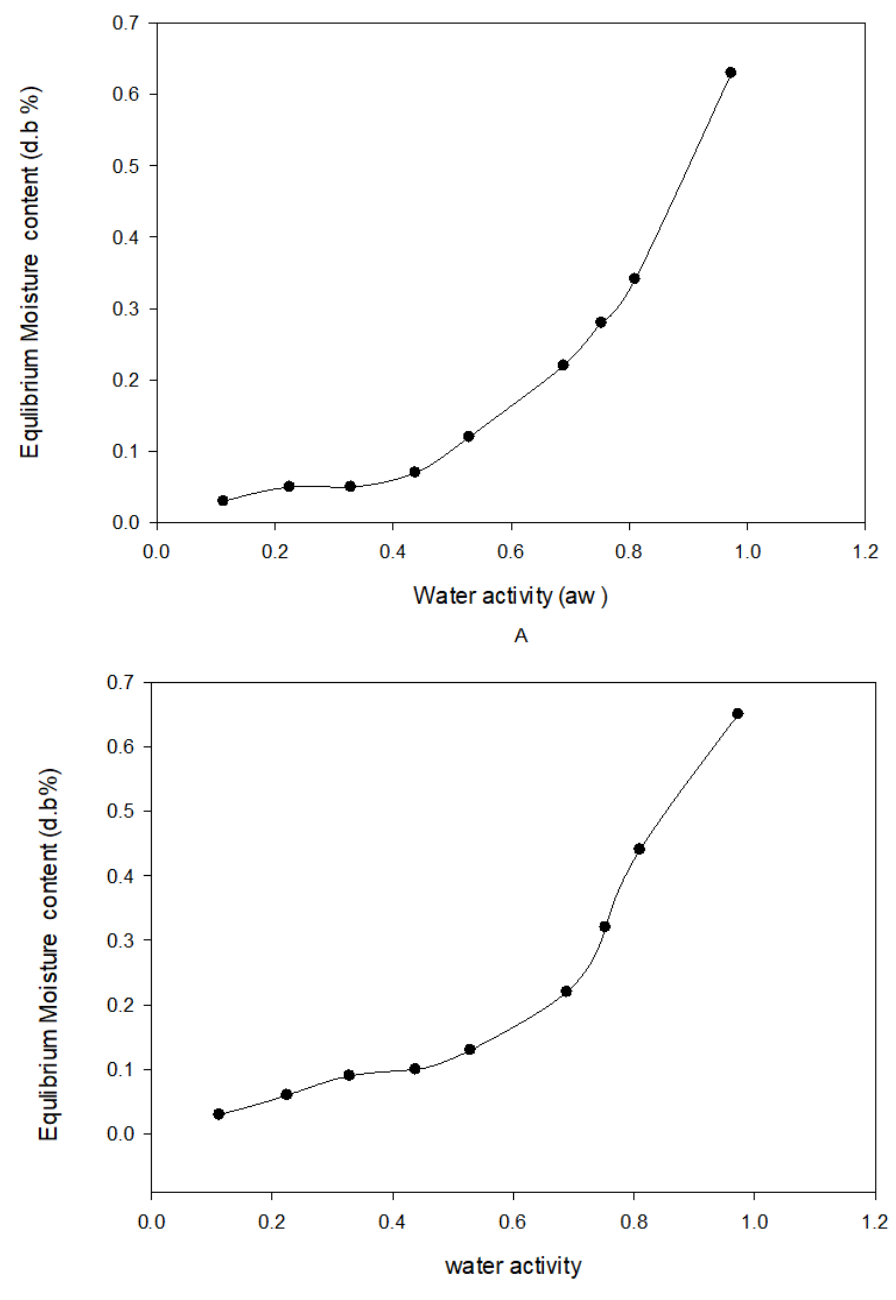

Figure 1. Moisture sorption isotherms of vacuum-dried jamun pulp powder $\mathrm{A}:\left(37^{\circ} \mathrm{C}\right) \mathrm{B}:\left(27^{\circ} \mathrm{C}\right)$ slight variation was observed on the equilibrium moisture content of the vacuum-dried sample. These results might be due to the hygroscopicity of the powder. These results suggest that the absorption on the porous microparticles will have resulted with type III isotherms (Admson, 1990). The composition of amorphous sugars is very important in determining the sorption behaviour and stickiness of a multi-component food powder. This pattern was observed commonly on high sugar content food products. According to the study of Garrone et al. (2010), the interaction points on the isotherm model depends mainly based on the type of sugar present and sugar size distribution in food samples.
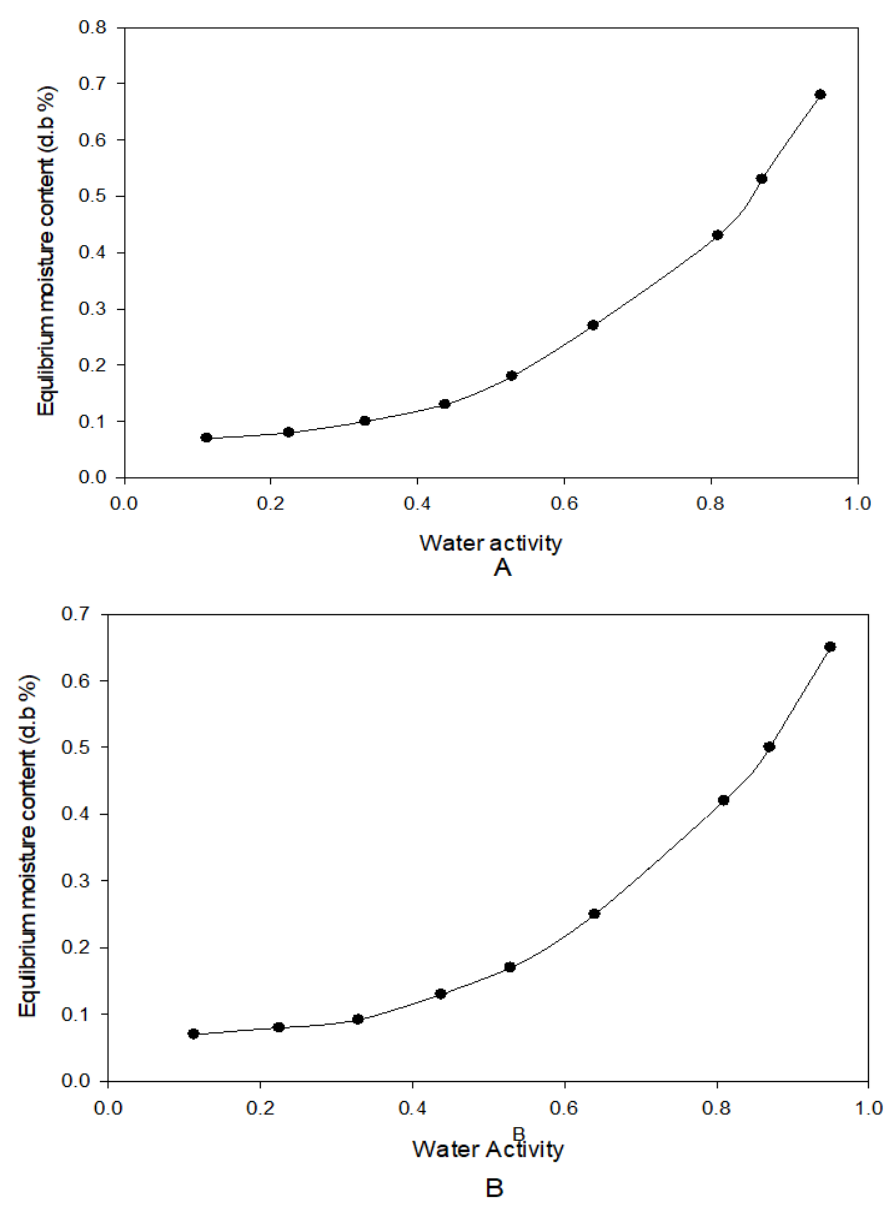

Figure 2. Moisture sorption isotherms of freeze-dried jamun pulp powder A: $\left(37^{\circ} \mathrm{C}\right) \mathrm{B}:\left(27^{\circ} \mathrm{C}\right)$

On top of that, the freeze-dried powder results with polar sites in molecular structure material which was occupied with water in wet conditions. During drying the molecules which were holding the water particles were attracted closely to each other. This significantly reduces the water holding capacity of the material on subsequent adsorption. The freeze-dried jamun pulp powder has a high degree of hygroscopicity as it intends to take the moisture greater to $50 \%$ on its dry weight. This moisture absorption occurs during the storage of freeze powder for one week under certain conditions (RH is less than 90\%). The phenomenon of deliquescence is important in freeze -dried powders because the exposure of solids to high $\mathrm{RH}$ results in the formation of a liquid phase where 
chemical reactions may be accelerated or physical changes catalysed (Callahan et al., 1988).

\subsection{Moisture sorption isotherm modelling}

The experimental moisture content on sorption study for freeze and vacuum-dried jamun pulp at $27^{\circ} \mathrm{C}$ and $37^{\circ}$ $\mathrm{C}$ were fitted to Henderson, Hasley, Iglesias and Chirife and $\mathrm{GAB}$ equation using nonlinear regression analysis are shown in the Table 1. Models are used to show the relationship between the equilibrium moisture content, water activity and temperature VD and FD jamun pulp powder. On most of the food and biological substances, the adsorption curves will be sigmoid as suggested by Sopade et al. (2010). The coefficient ranges between 0.8153 to 0.9592 on $27^{\circ} \mathrm{C}$ and 0.8515 to 0.9632 on $37^{\circ} \mathrm{C}$ on the adsorption model for freeze-dried jamun pulp powder. The adsorption model coefficient ranges between 0.7739 to 0.9533 on $37^{\circ} \mathrm{C}$ and 0.7811 to 0.9114 on $27^{\circ} \mathrm{C}$ of vacuum-dried jamun pulp powder.

To determine the goodness of fit, the models have to be suggested with coefficient determination, RMSE and Chi-square values (Kaymak et al., 2004). The data obtained in Table 1 and Table 2 suggests that comparing the value models run for sorption isotherm with high $\mathrm{R}^{2}$ which is close to one, lowest values of Chi-square and RMSE close to zero value of Henderson model describes the goodness of fit in adsorption study in the water activity and temperature range study of freeze-dried jamun pulp powder. However, the GAB equation was fitted as the best fit for vacuum-dried jamun pulp powder on both $27^{\circ} \mathrm{C}$ and $37^{\circ} \mathrm{C}$ sorption studies are shown in Table 3 and Table 4. In overall evaluation on vacuumdried samples. The GAB model is not so surprising based on its semi theoretical and homogenous adsorption has been suggested as a versatile sorption model available (Al-Muhtaseb et al., 2008). According to Van der Berg and Bruin (1980), it is clear that the $\mathrm{C}$ and $\mathrm{K}$ parameters incorporate the effect of temperature. Whereas this $\mathrm{C}$ and $\mathrm{K}$ are enthalpy and entropic in nature which suffices temperature effect on sorption models.

\section{Conclusion}

The study on sorption isotherms was carried out on freeze-dried and vacuum shelf dried powder. The important thermodynamic tool used for the interaction between food components and water is the sorption isotherm. These results gave a suitable model to fit sorption behaviour. Temperature affected the sorption behaviour, with equilibrium moisture content decreased with increasing temperature at constant water activity. On comparing the value models run for sorption isotherm with high $\mathrm{R}^{2}$ which is close to one, lowest values of Chi-square and RMSE close to zero value of
Henderson model describes the goodness of fit in adsorption study in the water activity and temperature range study of freeze-dried jamun pulp powder. The GAB model is not so surprising based on its semi theoretical and homogenous adsorption has been suggested as a versatile sorption model. In general, it can be concluded that among the dried pulp powder freezedried powder can be recommended for long term storage of jamun pulp powder.

\section{Acknowledgments}

I like to thank the Department of Food Processing and Engineering Karunya Institute of Technology and Science, Coimbatore for providing a wide space to do the research project. I like to thank all the lab assistants and my external examiner for helping me to finish this project work. I am so glad to work with the Department of Food Technology, KARE, Srivilliputtur.

\section{References}

Admson, A.W. (1990). Physical chemistry of surfaces. $5^{\text {th }}$ ed., p. 67-69. New York, USA: John Wiley and Sons.

Akpinar, E.K. and Bicer, Y. (2005). Modelling of the drying of eggplants in thin-layers. International Journal of Food Science and TechnAology, 40(3), 273-281. https://doi.org/10.1111/j.13652621.2004.00886.x

Al-Muhtaseb, S.A., El-Naas, M.H. and Abdallah, S. (2008). Removal of aluminum from aqueous solutions by adsorption on date-pit and BDH activated carbons. Journal of Hazardous Materials, 158(2-3), 300-307. https://doi.org/10.1016/ j.jhazmat.2008.01.080

Bajpai, S. and Tiwari, P. (2013). Investigation of Moisture Sorption Behavior of an Indian Sweet 'Son -Papdi'. Journal of Microbiology, Biotechnology and Food Sciences, 26(5), 2277-2282. https:// doi.org/10.9755/ejfa.v26i5.15749

Bianco, A.M., Boente, G., Pollio, M.L. and Resnik, S.L. (2001). Influence of oil content on sorption isotherms of four varieties of peanut at $25^{\circ} \mathrm{C}$. Journal of Food Engineering, 47(4), 327-331. https:// doi.org/10.1016/S0260-8774(00)00128-X.

Callahan, J., Hopking, D., Hopkins., Weiser, M. and Shneiderman, B. (1998) "An Empirical Comparison of Pie vs. Linear Menus ACM conference on huma factor on computing system $C H I^{\prime} 88,1988,98-100$. https://doi.org/10.1145/57167.57182

Catelam, K.T., Trindade, C.S.F. and Romero, J.T. (2011). Water adsorption isotherms and isosteric sorption heat of spray-dried and freeze-dried 


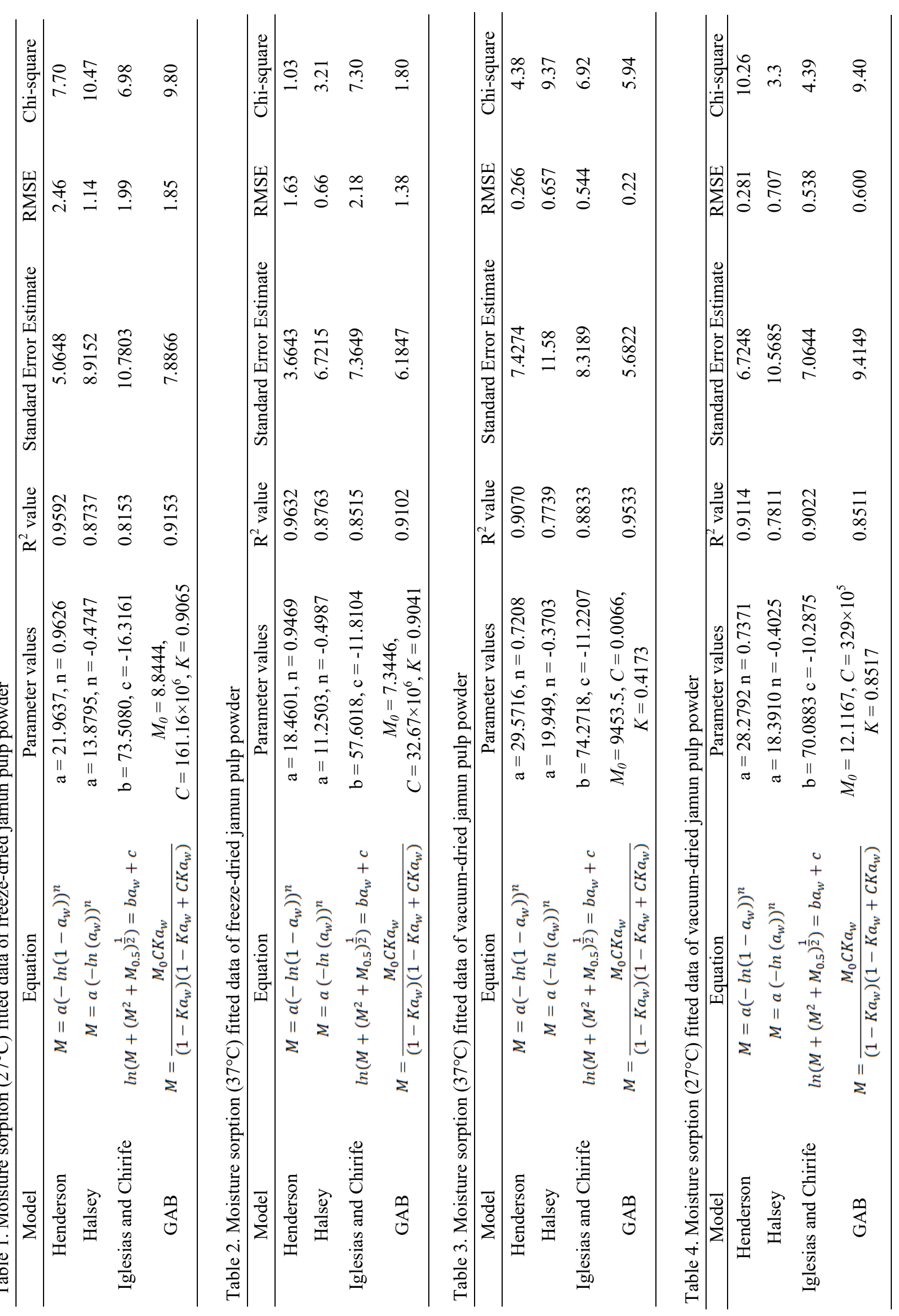


dehydrated passion fruit pulp with additives and skimmed milk. Ciência e Agrotecnologia, 35(6), 1196-1203. https://doi.org/10.1590/S141370542011000600021

Garrone, E., Rouquérol, F., Fubini, B. and Della Gatta, G. (2010). Entropy of adsorption and related thermodynamic functions in an open isothermal system. Journal of Physical Chemistry, 76, 528-532. https://doi.org/10.1051/jcp/1979760528

Gondek, E. and Lewicki, P.P. (2005). Moisture sorption isotherms of dried and candied fruits. Acta Scientiarum Polonorum Technologia Alimentaria, 4 (1), 63-71.

Heinonen, M. (2007). Antioxidant activity and antimicrobial effect of berry phenolics- a Finnish perspective. Molecular Nutrition and Food Research, 51(6), 684-691. https://doi.org/10.1002/ mnfr.200700006

Kaymak-Ertekin, F. and Gedik, A. (2004). Sorption isotherms and isosteric heat of sorption for grapes, apricots, apples and Potatoes. LWT - Food Science and Technology, 37(4), 429-438. https:// doi.org/10.1016/j.lwt.2003.10.012

Lomauro, C.J., Bakshi, A.S. and Labuza, T.P. (1985). Evaluation of food moisture sorption isotherm equations, Fruit, vegetable and meat products. Lebensmittel-Wissenschaft und Technologie, 18(2), 111-117.

Prothon, F. and Ahrné, L.M. (2004). Application of the Guggenheim, Anderson and De Boer model to correlate water activity and moisture content during osmotic dehydration of apples. Journal of Food Engineering 61(3), 467-470. https://doi.org/10.1016/ S0260-8774(03)00119-5

Silva, P., Aznar, S., Aires, S., Generelo, E., Zaragoza, J. and Mota, J. (2010). Differences in the physical activity pattern between Portuguese and Spanish adolescents. Archives in Exercise and Health Diseases, 1(1), 26-31. https://doi.org/10.5628/ aehd.v1i1.78

Sopade, P.A., Ajisegiri, E.S.A., Chukwu, O. and Abass, A.B. (2010). Moisture-sorption isotherms of Irish and sweet potatoes. Journal of Food Process Engineering, 33(3), 385-397. https:// doi.org/10.1111/j.1745-4530.2007.00190.x

Stamatios, B. and Vassilios, G.B. (2004). Influence of the drying conditions on the drying contents and moisture diffusivity during the thin layer drying of figs. Journal of Food Engineering, 65(3), 449-458. https://doi.org/10.1016/j.jfoodeng.2004.02.005

Szajdek, A. and Borowska, E. (2008). Bioactive compounds and health-promoting properties of berry fruits: a review. Plant Foods for Human Nutrition, 63, 147-156. https://doi.org/10.1007/s11130-0080097-5

Van der Berg, C. and Bruin, S. (1981) Water activity and its estimation in food systems. In Rockland, L.B. and Stewarts, G.F. (Eds). Theorical Aspects in Water Activity: Influence on Food Quality, p. 12-45. New York, USA: Academic Press. https:// doi.org/10.1016/B978-0-12-591350-8.50007-3 